\title{
The Effect of Factors on the Radiation Noise of High-Speed Full Ceramic Angular Contact Ball Bearings
}

\author{
Haipeng Yan, ${ }^{1,2}$ Yuhou Wu $\mathbb{D}^{1,2}$ Songhua Li, ${ }^{1,2}$ Lixiu Zhang, ${ }^{1,2}$ and Ke Zhang ${ }^{1,2}$ \\ ${ }^{1}$ School of Mechanical Engineering, Shenyang Jianzhu University, Shenyang 110168, China \\ ${ }^{2}$ National-Local Joint Engineering Laboratory of NC Machining Equipment and Technology of High-Grade Stone, \\ Shenyang 110168, China
}

Correspondence should be addressed to Yuhou Wu; wuyh@sjzu.edu.cn

Received 18 October 2018; Accepted 26 November 2018; Published 12 December 2018

Academic Editor: Zhixiong Li

Copyright (c) 2018 Haipeng Yan et al. This is an open access article distributed under the Creative Commons Attribution License, which permits unrestricted use, distribution, and reproduction in any medium, provided the original work is properly cited.

Ceramic angular contact ball bearing is widely used in a high-speed motorised spindle because of their excellent properties such as wear resistance, high temperature resistance, and corrosion resistance. In this study, the characteristics and influencing factors of the radiation noise for a full ceramic angular contact ball bearing applied in the motorised spindle are investigated. Based on a single factor test method, the variations of bearing noise with preload, oil supply, and rotation speed were investigated, and then, the optimal preload and oil supply under the specific speed were obtained. The sound field directivity in the circumferential distribution of the bearing noise was discussed, and the reasons for the uneven distribution of the sound field were elucidated. According to the experimental results, a prediction model on the radiation noise of a full ceramic angular contact ball bearing under certain conditions was proposed. The conclusions will provide a reference for reducing the radiation noise of full ceramic angular contact ball bearings in high-speed operation and improving the bearing performance.

\section{Introduction}

Bearings, a key component for the mechanical system, are required to have high precision and reliability [1]. Full ceramic bearings (FCBs) are made of a new type of ceramic materials. They have excellent properties such as corrosion resistance, wear resistance, and thermal stability. Furthermore, they can replace steel bearings. Therefore, FCBs are widely applied to industrial machinery, medical devices, aerospace, navigation, and other fields. However, due to the hardness and brittleness of ceramic materials, the FCBs bring excessive radiation noise during the operation, which affects the performance of bearings and generates serious noise pollution to the surrounding acoustic environment. The radiation noise of bearings is affected by many factors, such as preload, lubrication condition, working speed, and structural characteristics. For the FCBs applied in the motorised spindle, the radiation noise can reflect their operation accuracy and reliability to a certain extent. Moreover, the sound field directivity of the radiation noise is also an important evaluation index for acoustic performance and noise environment. Researches on the influence factors and the distribution characteristics of radiation noise for the FCBs are conducive for further improving their working conditions, extending their service life, and increasing their reliability.

Many researchers have developed the dynamic model of angular contact bearings. The effects of preload [2], stiffness [3], contact angle [4], raceway surface roughness [5], and waviness [6] on the dynamic characteristics of the bearing are analysed in particular, as well as skidding behaviour [7, 8]. For example, Gunduz et al. [2] investigated the vibration response of angular contact ball bearings with respect to bearing preload and proved that the bearing preloads had a significant effect on the vibration characteristics of a shaft-bearing assembly. Zhang et al. [9] researched the impact of the lubricant traction coefficient on cage's dynamic characteristics in high-speed angular contact bearing, and the stability of a cage under various working conditions were assessed by using the slip ratio of the cage. 
Xi et al. [10] presented a dynamic model of the spindle bearing system to investigate the dynamic responses of the machine tool spindle, and the simulated results of the proposed model were validated by experimental results. In addition, some researchers discussed the thermal characteristics of bearings, lubrication, and air supply method [11-15] as well as the dynamic response with fault conditions $[16,17]$. In recent years, researchers are interested in the acoustic characteristics of bearings, such as monitoring the bearing faults through acoustic signals $[18,19]$ and calculating the radiation noise of ceramic bearings by the subsource decomposition method [20]. Because of the particularity of ceramic materials, the contact deformation between ceramic bearing components and its lubrication mode are much different from that of steel bearings. However, the research on the performance of FCBs is quite rare.

The noise of a motorised spindle mainly derives from the bearing vibration of the supporting spindle. This study focuses on the property of radiation noise produced by the full ceramic angular contact ball bearing applied to a motorised spindle. The effects of the bearing preload, oil supply, and rotation speed on the radiation noise of a full ceramic angular contact ball bearing are discussed by a single factor test. Then, the distribution characteristics of the bearing noise in the circumferential direction are analysed. On the basis of experiments, a prediction model on the radiation noise of a full ceramic angular contact ball bearing is presented. This study provides a sufficient experimental basis for reasonably setting the working conditions and improving the performance of FCBs.

\section{Experimental Method}

A test rig for measuring the noise was built in the standard laboratory. The environmental temperature in the laboratory was $26^{\circ} \mathrm{C}$. The background noise in the experiment was lower than $45 \mathrm{~dB}$. The type of the measured motorised spindle is $150 \mathrm{MD} 18 \mathrm{Y} 14.5$, and its performance parameters are shown in Table 1. The type of the bearings used in the motorised spindle is $\mathrm{H} 7009 \mathrm{C}$. The materials of the bearing rings, balls, and cage are zirconia ceramics, silicon nitride ceramics, and bakelite, respectively. The structural parameters of the bearing are listed in Table 2. The motorised spindle and its supporting bearing are shown in Figure 1.

A water cooling system and an oil-gas lubrication system were applied to the cooling and lubrication of the motorised spindle. The cooling temperature was set constant at $18^{\circ} \mathrm{C}$. The engine oil with \#30 was used for bearing lubrication. The pressure of oil supply was $0.25 \mathrm{MPa}$. The flow rate of cooling water was set to $4.7 \mathrm{~L} \cdot \mathrm{min}^{-1}$. The motorised spindle maintains a steady-state operation without external load during the test. To investigate the radiation noise characteristics of a full ceramic angular contact ball bearing, the effects of bearing preload, lubricating oil supply, and rotation speed on the radiation noise of the full ceramic angular contact ball bearing were studied by a single factor experimental method. The test parameters and levels are shown in Table 3. The bearing preload was adjusted by a spring, the oil supply was
TABLE 1: Performance parameters of the motorised spindle.

\begin{tabular}{lc}
\hline Parameter & Value \\
\hline Rated power $(\mathrm{kW})$ & 14.5 \\
Rated voltage $(\mathrm{V})$ & 350 \\
Rated current $(\mathrm{A})$ & 32 \\
Rated frequency $(\mathrm{Hz})$ & 300 \\
Rated speed $\left(\mathrm{r} \cdot \mathrm{min}^{-1}\right)$ & 18000 \\
\hline
\end{tabular}

TABLE 2: Structural parameters of the ceramic bearing.

\begin{tabular}{lc}
\hline Parameter & Value \\
\hline Bearing outside diameter $(\mathrm{mm})$ & 75 \\
Inner ring bore diameter $(\mathrm{mm})$ & 45 \\
Bearing width $(\mathrm{mm})$ & 16 \\
Cage outside diameter $(\mathrm{mm})$ & 63.5 \\
Pocket diameter $(\mathrm{mm})$ & 8.9 \\
Cage width $(\mathrm{mm})$ & 14 \\
Ball diameter $(\mathrm{mm})$ & 8.731 \\
Ball number & 17 \\
Initial contact angle $\left(^{\circ}\right)$ & 15 \\
\hline
\end{tabular}

controlled by a programmable logic controller, and the rotation speed was adjusted by a frequency converter.

As shown in Figure 2, the 12 measuring points are selected to analyse the radiation noise of the FCB applied in the motorised spindle. All points were arranged in a plane in front of the spindle, and the plane was $200 \mathrm{~mm}$ away from the bearing plane. The measuring points were evenly distributed in the circumferential direction with $150 \mathrm{~mm}$ away from the center line of the bearing. The angle between the adjacent two measuring points was $30^{\circ}$. The first measuring point was above the motorised spindle, and the direction was set to $0^{\circ}$. The 12 measuring points were arranged in the counterclockwise direction and numbered in sequence. The sound pressure sensors were placed at the measuring points.

During the experiment, the sound pressures were measured using the INV9206-I sound pressure sensors with sensitivities from 50 to $54.5 \mathrm{mV} \cdot \mathrm{Pa}^{-1}$. The dynamic measuring range of the sensors is from 20 to $146 \mathrm{~dB}$, and their frequency response range is from 20 to $20000 \mathrm{~Hz}$. The sound pressure sensors are calibrated by the HS6020 acoustic calibrator, which is a single frequency of the sound wave with $1000 \mathrm{~Hz}$, with a constant SPL of $94.0 \mathrm{~dB}$ and a harmonic distortion of $0.7 \%$. The sound pressure signals of each measuring point were collected by the INV3060S data collector and processed using the Coinv DASP-V10 acoustic interface software. All the measuring instruments are developed by the China Orient Institute of Noise and Vibration. The sampling frequency and sampling time were $51.2 \mathrm{kHz}$ and $10 \mathrm{~s}$, respectively. The collected data were transmitted to the computer to further process the sound pressure data and analyse the radiation sound field characteristics of the full ceramic angular contact ball bearing.

\section{Results and Discussion}

Sound pressure level (SPL) which is linearly weighted is used to evaluate the magnitude of the bearing noise in this study. 


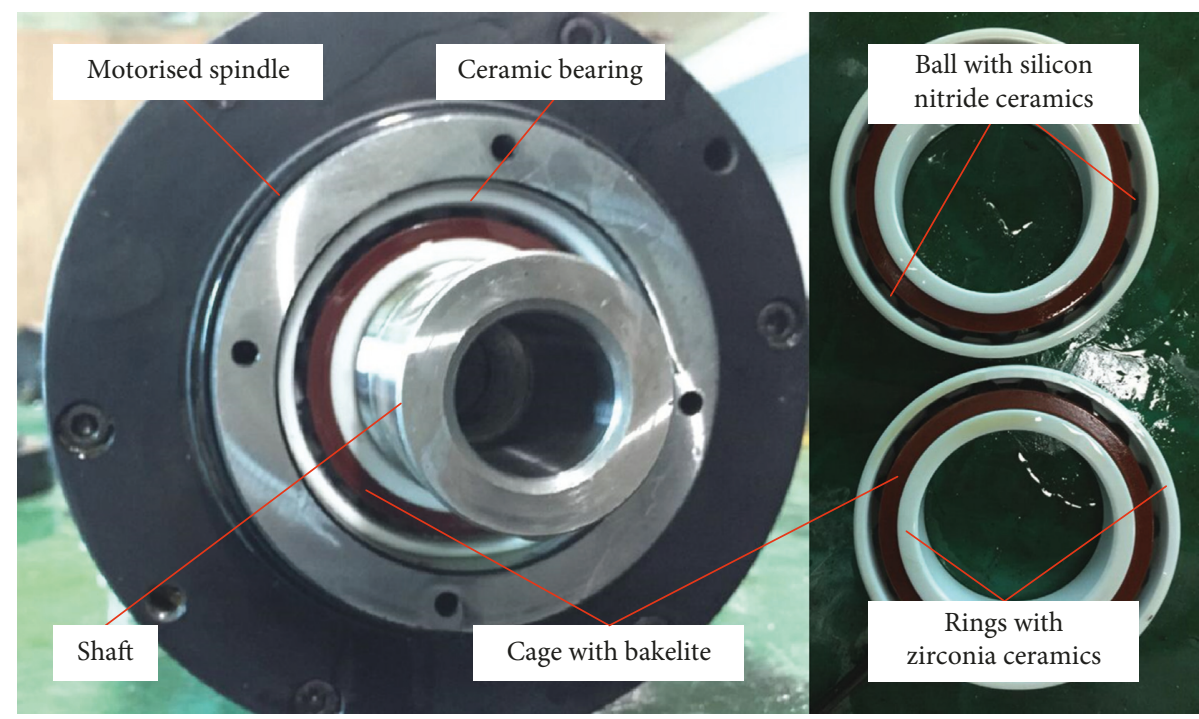

FIgURE 1: Motorised spindle and FCB.

TABLE 3: Test parameters and levels.

\begin{tabular}{lccc}
\hline Level & Preload $(\mathrm{N})$ & Oil supply $\left(\mathrm{mL} \cdot \mathrm{min}^{-1}\right)$ & Speed $\left(\mathrm{r} \cdot \mathrm{min}^{-1}\right)$ \\
\hline 1 & 250 & 0.01 & 3000 \\
2 & 300 & 0.015 & 6000 \\
3 & 350 & 0.02 & 9000 \\
4 & 400 & 0.025 & 12000 \\
5 & 450 & 0.03 & 15000 \\
6 & 500 & 0.035 & 18000 \\
\hline
\end{tabular}

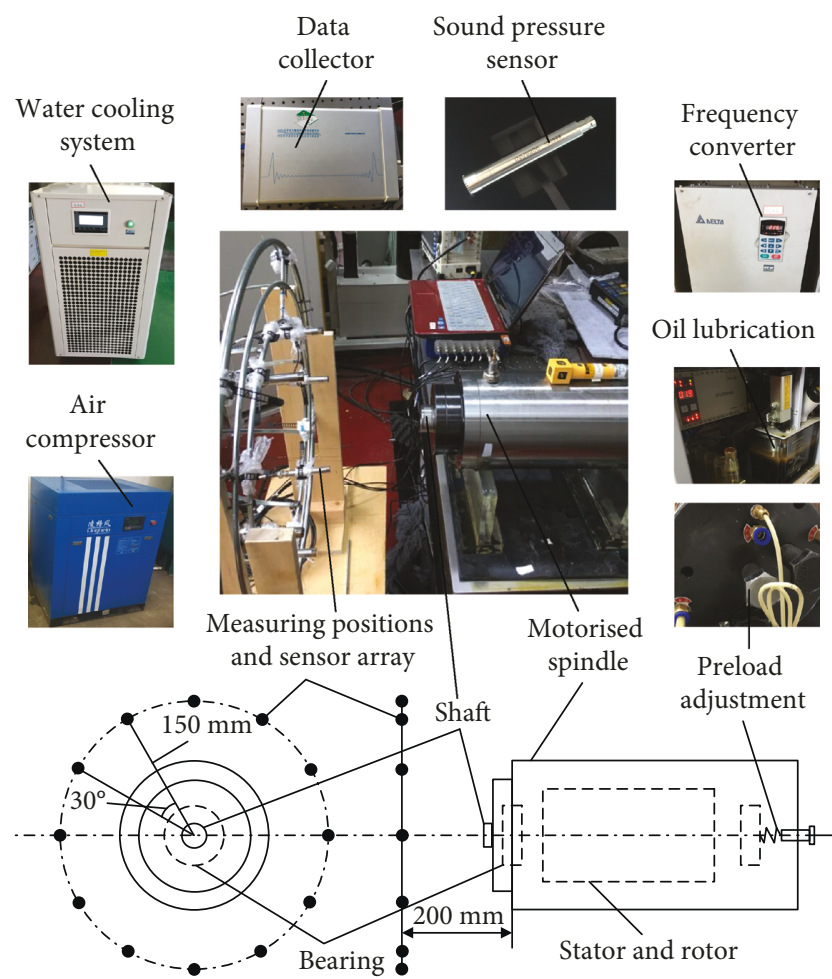

FIgURE 2: Experimental apparatuses and measurement scheme.
The frequency of $1024 \mathrm{~Hz}$ was applied during the signal processing, and then a total data number of 500 on the SPL were obtained. The average value of the SPLs was used to analyse the radiation noise of the FCB. In this study, directivity angle (DA) of sound field is defined as the position angle of the radiation noise peak value in the whole circumferential direction or within a range. It is also the direction angle of sound field directivity. The DA presents the inflection point of radiation noise change in the circumferential direction and reflects the direction of maximum noise within a certain range. The effects of bearing preload, oil supply, and rotation speed on the radiation noise of a full ceramic angular contact ball bearing are analysed in detailed as follow.

3.1. Effect of Preload on the Radiation Noise. The preload is widely used to eliminate clearance and prevent skidding $[7,21]$. An appropriate preload can improve the bearing service life [22]. However, an excessive preload may lead to large deformations on the balls and raceways and bring about extrafriction and noise [23]. To analyse the effect of preload on the radiation noise of the full ceramic angular contact ball bearing, the rotation speed was set to 18000 $\mathrm{r} \cdot \mathrm{min}^{-1}$ and the oil supply was set to $0.02 \mathrm{~mL} \cdot \mathrm{min}^{-1}$. During the test, six groups of experiments with the preloads of $250 \mathrm{~N}, 300 \mathrm{~N}, 350 \mathrm{~N}, 400 \mathrm{~N}, 450 \mathrm{~N}$, and $500 \mathrm{~N}$, respectively, were conducted. Figure 3 shows the distribution of the radiation noise in the circumferential direction under different preloads. Figure 4 shows the DA of sound field and the curve of SPL in the directivity direction varying with preloads.

As shown in Figure 3, under all preloads, the radiation noises of FCBs present nonlinear variation in the circumferential direction and show obvious sound field directivity. There are two directions of sound field directivity, and the 


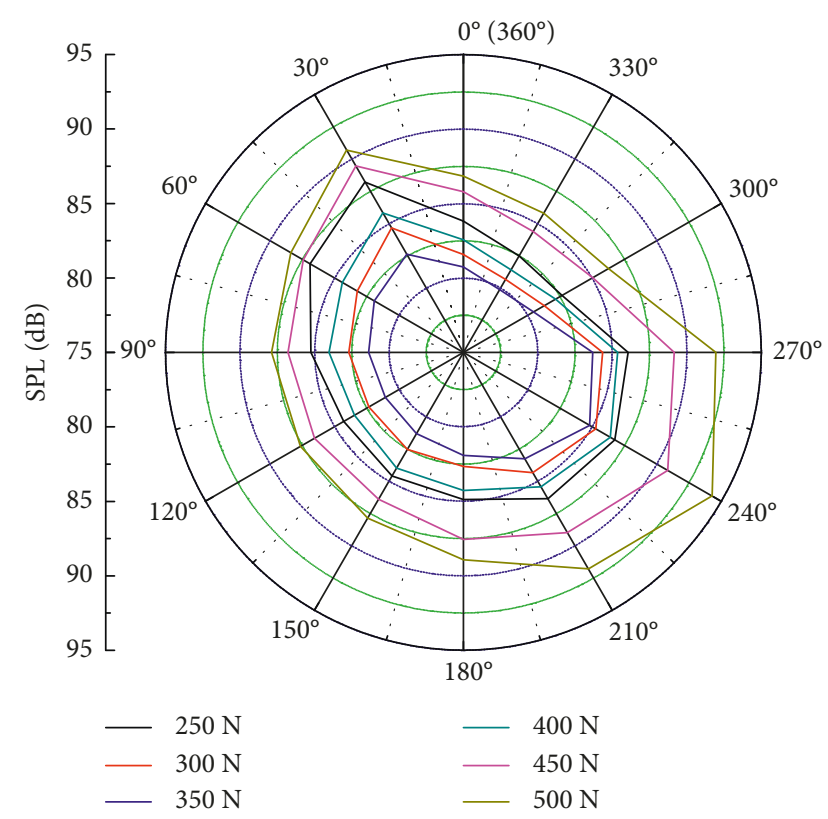

Figure 3: Radiation noise of the ceramic bearing with different preloads.

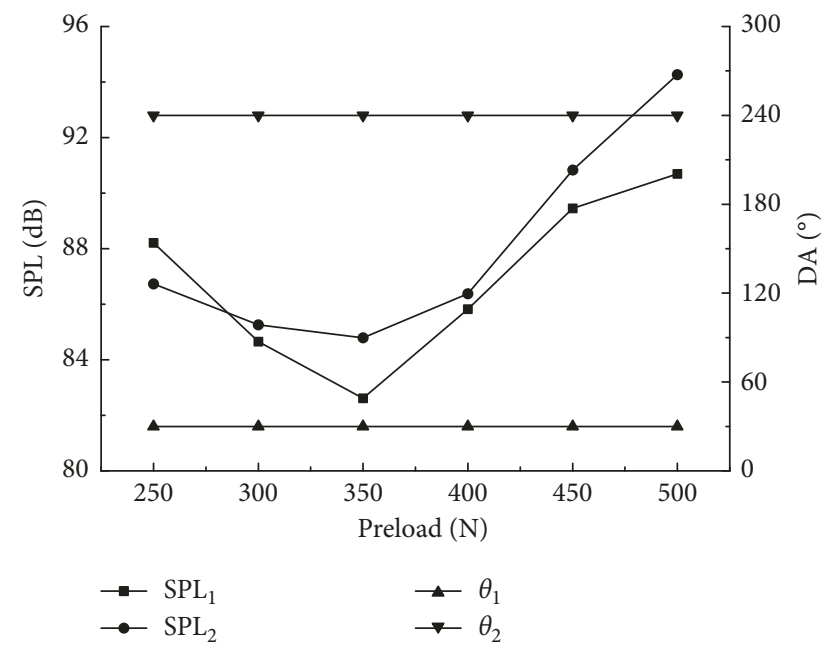

FIGURE 4: Variation trends of DAs and their SPLs with preload.

DAs are $\theta_{1}$ and $\theta_{2}$ in the directions of $30^{\circ}$ and $240^{\circ}$, respectively. The radiation noise in the ranges of $0-60^{\circ}$ and $180-300^{\circ}$ varies greatly, while its variation in the ranges of $60-180^{\circ}$ and $300-360^{\circ}$ is slow. The radiation noise in the range of $60-180^{\circ}$ is slightly greater than the noise in the range of $300-360^{\circ}$. The radiation noise decreases first and then increases with increasing the preload from $250 \mathrm{~N}$ to $500 \mathrm{~N}$. The minimum radiation noise occurs at a preload of $350 \mathrm{~N}$, which can be considered the optimum preload [24] for the bearing at $18000 \mathrm{r} \cdot \mathrm{min}^{-1}$. A great impact noise caused by the ceramic ball and cage is in the range of $0-60^{\circ}$, which can be called the impact load zone. A great friction noise caused by the ceramic ball and rings in the range of $180-300^{\circ}$ is defined as the friction load zone. The radiation noise in the impact load zone is slightly higher than that in the friction load zone at a low preload. With the increase of preload, the radiation noise in the friction load zone becomes gradually larger than the radiation noise in the impact load zone.

It can be seen more directly from Figure 4 that the radiation noise of the bearing has a minimum SPL at a preload of $350 \mathrm{~N}$, and the DAs remain basically unchanged with the directions of $0^{\circ}$ and $240^{\circ}$, respectively. The increase of preload intensifies the friction and impact of bearing, which results in the increase of bearing noise. However, the maximum positions of friction and impact are basically unchanged, and thus the DAs of sound field are almost unchanged.

Under different preloads, the ceramic ball and cage produce a large impact noise near $30^{\circ}$ direction, and the ceramic ball and rings produce a large friction noise near $240^{\circ}$ direction, leading to that the full ceramic angular contact ball bearing has obvious sound field directivity. The increase of the preload contributes to the friction and impact noise, resulting in more obvious sound field directivity. When in a low value of preload, the impact noise is more prominent than the friction noise because that bearing has a big clearance, and the active space of the ceramic ball is large. At this point, both contact force and friction force acting on the ball are small. On the contrary, when the preload has a big value, the bearing clearance is small. The increase of the friction forces between the rings and the balls results in the larger friction noise. In addition, a big impact noise is produced between the balls and the cage during the highspeed operation, but its value is slightly lower than the friction noise. There will be a deadlock or a wear fault for the bearing in a serious case [25]. Therefore, the excessive preload should be avoided.

3.2. Effect of Oil Supply on the Radiation Noise. Lubrication is required for all bearings during the operation, and it can reduce friction between bearing components $[26,27]$. Moreover, the lubrication condition is vital during bearing operation. To analyse the effect of oil supply on the radiation noise of the full ceramic angular contact ball bearing, the rotation speed was set to $18000 \mathrm{r} \cdot \mathrm{min}^{-1}$, and the preload was set to $350 \mathrm{~N}$. During the test, six groups of experiments with the oil supply of $0.01 \mathrm{~mL} \cdot \mathrm{min}^{-1}$, $0.015 \mathrm{~mL} \cdot \mathrm{min}^{-1}, \quad 0.02 \mathrm{~mL} \cdot \mathrm{min}^{-1}, \quad 0.025 \mathrm{~mL} \cdot \mathrm{min}^{-1}, \quad$ and $0.03 \mathrm{~mL} \cdot \mathrm{min}^{-1}$ were carried out. Figure 5 shows the distribution of the radiation noise in the circumferential direction under different oil supply. Figure 6 shows the DA of sound field and the curve of SPL in the directivity direction varying with oil supply.

According to Figure 5, there are two obvious directions of sound field directivity in the circumferential distribution of bearing radiation noise. The two directions are in the impact load zone of $0-60^{\circ}$ and the friction load zone of $180-300^{\circ}$, respectively. The trends of sound field directivity tend to slightly weaken with the increase of oil supply. The radiation noises in the range of $60-180^{\circ}$ vary smoothly and are slightly larger than that in the range of $300-360^{\circ}$. The difference values of the SPLs between the two ranges tend to decrease with the increase of oil supply. In the direction of 


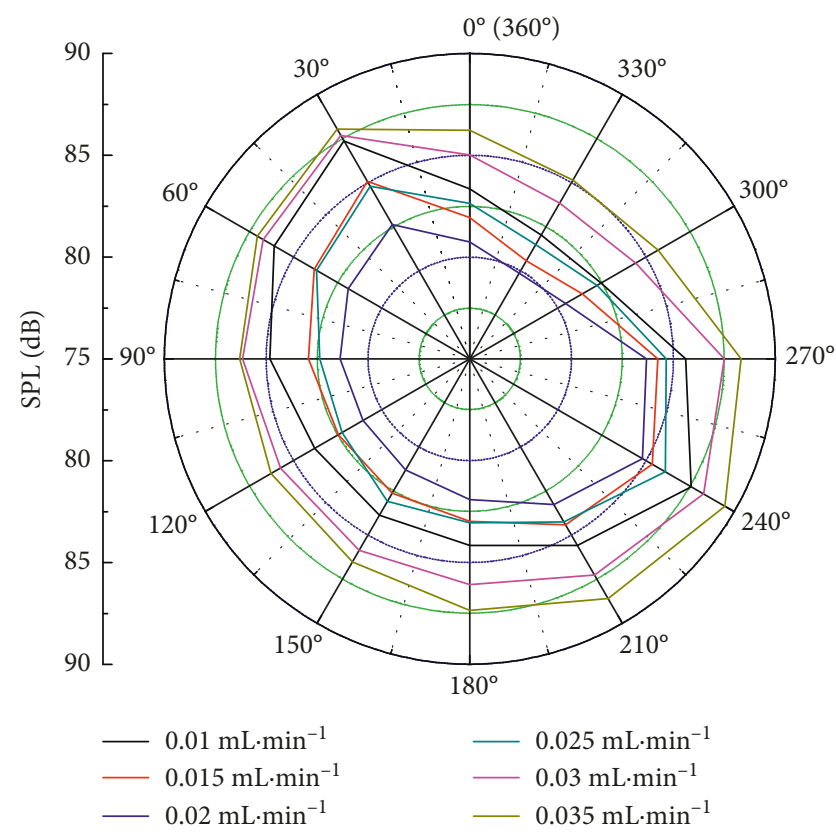

FIGURE 5: Radiation noise of the ceramic bearing under different oil supply.

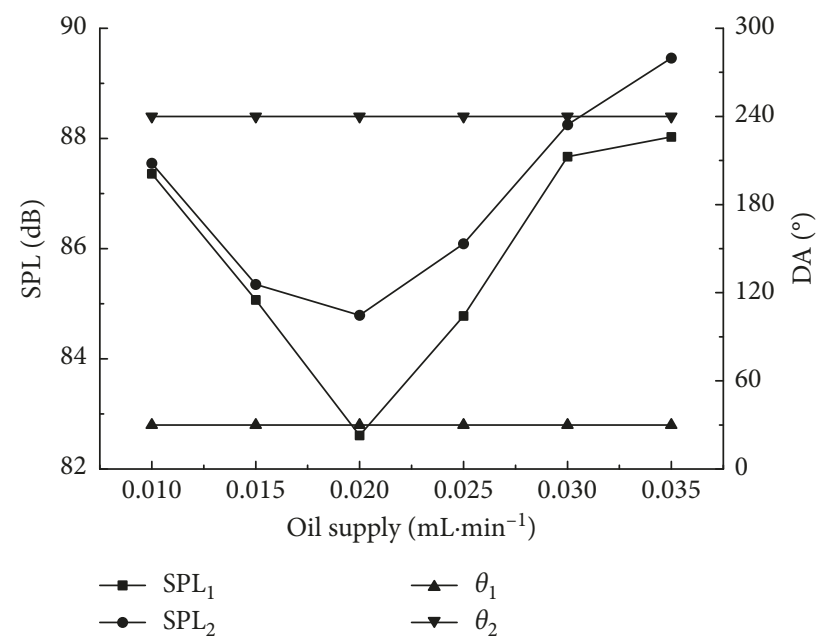

FIGURE 6: Variation trends of DAs and their SPLs with oil supply.

$330^{\circ}$, the radiation noises of the bearing reach the minimum value.

As shown in Figure 6, with the increase of the oil supply, the DA of the sound field remains unchanged, i.e., the oil supply does not affect the DA of the sound field. However, the SPLs in the two directions of the sound field directivity decrease first and then increase with the increase of oil supply. Moreover, the radiation noise in the friction load zone is larger than that in the impact load zone.

With the increase of oil supply, the radiation noise of FCBs decreases first and then increases. At the value of $0.02 \mathrm{~mL} \cdot \mathrm{min}^{-1}$, the bearing has the lowest radiation noise. In the condition with a preload of $350 \mathrm{~N}$ and speed of 18000 $\mathrm{r} \cdot \mathrm{min}^{-1}$, the oil supply of $0.02 \mathrm{~mL} \cdot \mathrm{min}^{-1}$ is the optimal oil supply for the bearing lubrication [28]. When the oil supply is too small, the bearing is in the boundary friction state, resulting in a bigger friction force and greater noise. When the oil supply is too large, although the bearing has a good lubricating state, a stirring oil temperature will be raised by a large margin, causing the high bearing working temperature. It can weaken the bearing clearance and further lead to greater friction noise. Therefore, at a certain speed and preload [29], the bearing has an optimum oil supply, which can make the bearing be under an excellent lubrication condition so as to reduce the radiation noise of the bearing.

To compare Figures 3 and 5, with the increase of preload and oil supply, the radiation noise of FCBs in the circumferential direction has similar distribution characteristics, and the DAs of the sound field remain unchanged. Compared with the preload, the oil supply has little effect on the radiation noise of the bearing. An excellent lubricating effect can be achieved with less lubricating oil due to the selflubricating effect of FCBs.

\subsection{Effect of Rotation Speed on the Radiation Noise. For high-} speed precision machine tools, a higher rotation speed for bearings is required and complex speed changes are needed. However, the optimum preload and oil supply under different rotation speeds are different $[30,31]$. According to the analysis in the above section, the optimum preload and oil supply for minimum noise of the bearing at $18000 \mathrm{r} \cdot \mathrm{min}^{-1}$ are nearly $350 \mathrm{~N}$ and $0.02 \mathrm{~mL} \cdot \mathrm{min}^{-1}$, respectively. Here, the preload and oil supply were set as optimal constant values. The radiation noise of a full ceramic angular contact ball bearing in the rotation speeds of $3000 \mathrm{r} \cdot \mathrm{min}^{-1}, 6000 \mathrm{r} \cdot \mathrm{min}^{-1}, 9000 \mathrm{r} \cdot \mathrm{min}^{-1}$, $12000 \mathrm{r} \cdot \mathrm{min}^{-1}, 15000 \mathrm{r} \cdot \mathrm{min}^{-1}$, and $18000 \mathrm{r} \cdot \mathrm{min}^{-1}$ was measured. The effect of the speed on radiation noise was investigated by using the six-group experiments. Figure 7 shows the distribution of radiation noise in the circumferential direction of FCB at different rotation speeds. Figure 8 shows the DA of sound field and the curve of the SPL in the directivity direction varying with the rotation speed.

Figure 7 illustrates that the radiation noise of FCB increases in general with the increase of speed, and the sound field directivity becomes more and more obvious. When the speed is low, the difference between the maximum and the minimum of the radiation noise in the circumferential direction is small; at the speed of $3000 \mathrm{r} \cdot \mathrm{min}^{-1}$, the value is $3.11 \mathrm{~dB}$. When the speed is high, the difference becomes larger because of the influence of variable friction and impact. At the speed of $18000 \mathrm{r} \cdot \mathrm{min}^{-1}$, the value is $4.93 \mathrm{~dB}$. It can be known from the circumferential distribution of the noise that the noise changes gently in the ranges of $60-180^{\circ}$ and $300-360^{\circ}$; however, there are two obvious directivity directions of the sound field in the ranges of $0-60^{\circ}$ and 180-300 .

As shown in Figure 8, as the speed increases, the DA $\theta_{1}$ of the sound field in the range of $0-60^{\circ}$ is almost invariable. In the range of $180-300^{\circ}$, the DA $\theta_{2}$ of the sound field varies gradually from $210^{\circ}$ to $240^{\circ}$ when the speed changed from $12000 \mathrm{r} \cdot \mathrm{min}^{-1}$ to $15000 \mathrm{r} \cdot \mathrm{min}^{-1}$, resulting in the directivity becomes clearer. With the increase of speed, the $\mathrm{SPL}_{1}$ in $\theta_{1}$ 


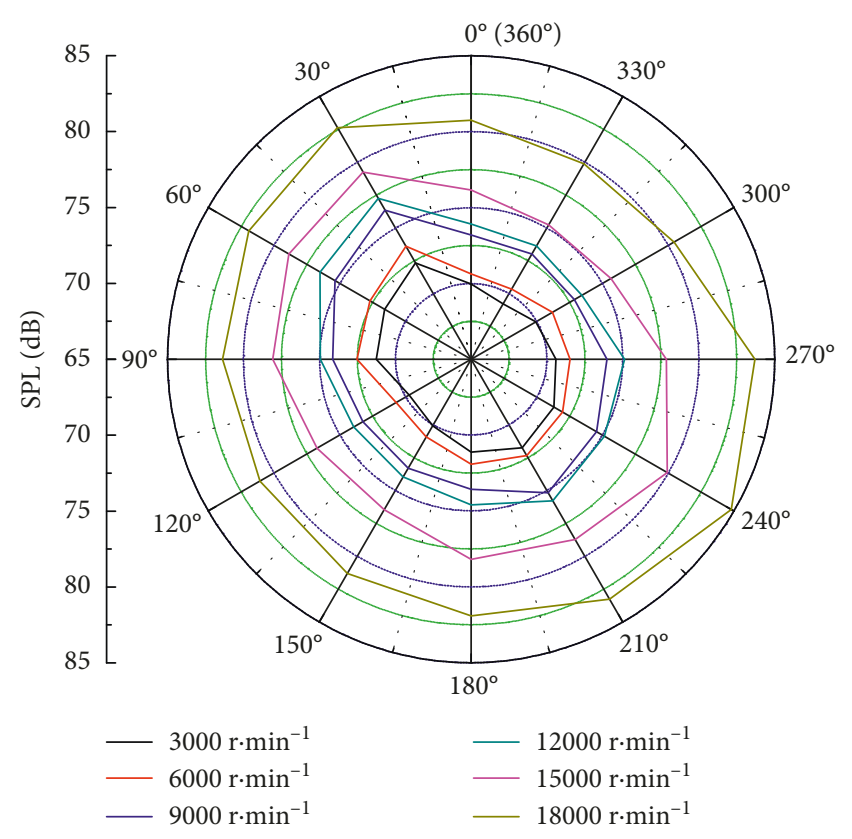

FIGURE 7: Radiation noise of the ceramic bearing at different speeds.

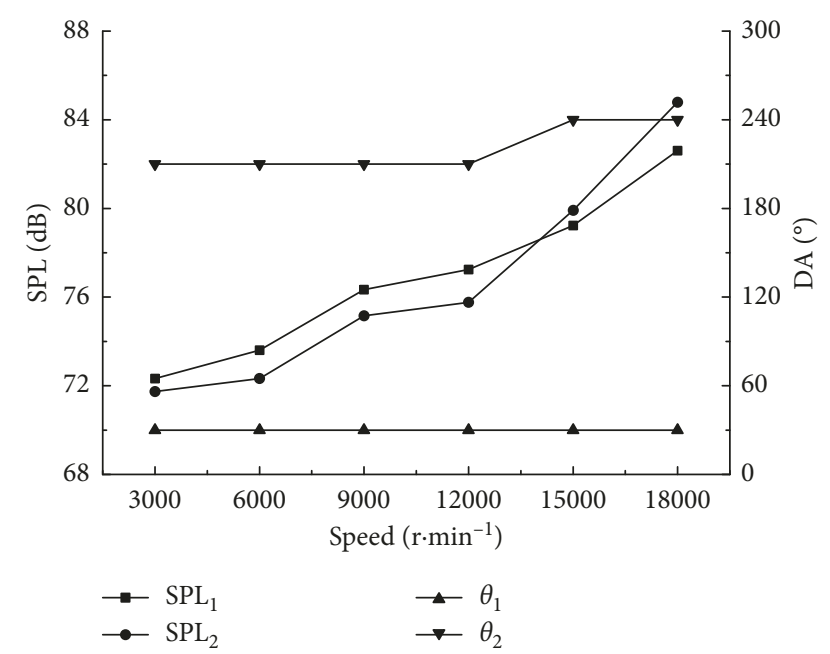

FIGURE 8: Variation trends of DAs and their SPLs with speed.

direction is from $72.32 \mathrm{~dB}$ to $82.61 \mathrm{~dB}$, and the $\mathrm{SPL}_{2}$ in $\theta_{2}$ direction is from $71.74 \mathrm{~dB}$ to $84.79 \mathrm{~dB}$. The inner ring of the bearing rotates counterclockwise resulting in the bearing eccentricity towards the lower right, so the friction load zone moves upwards along with the rotation direction. With the increase of the rotation speed, the centrifugal force of the ball increases rapidly $[32,33]$ and varies complex due to the bearing eccentricity. Then, the direction of the complex resultant force acting on the ball varies correspondingly. The increase of rotation speed causes the bearing eccentricity upwards, thus leading to the shift of the direction angle.

In addition, according to Figure 8, the friction is smaller and the impact is larger when the bearing is in the lower speed. Therefore, the impact noise is relatively greater than the friction noise at low speed. However, the increase of the rotation speed aggravates the friction. Although the impact noise also has an increasing tendency, it changed gently. Therefore, the directivity direction of sound field in the impact load zone is dominant at lower rotation speed, while at higher speed, the direction is replaced by the friction load zone. As the rotation speed has a significant influence on the bearing dynamic properties and stiffness [34, 35], when the bearing operates at high speed, bearing stiffness is relatively small, and a great alternating force between the ball and the rings will make the balls be prone to skid and bring impact noise. The larger friction force will be caused in the friction load zone, resulting in the larger friction noise. The obvious sound field directivity will lead to bearing failure due to the serious wear phenomenon caused by violent friction.

\section{Prediction Model on the Radiation Noise of FCBs}

According to the analysis in section 3, the radiation noise of full ceramic angular contact ball bearings with the type of H7009C is a function of preload, oil supply, and rotation speed. In addition, the radiation noise is also related to the circumferential angle. Through the analysis of the experimental data, the polynomial models between the radiation noise and the preload and between the oil supply and the speed are established using the least squares method. The models are shown in Equations (1)-(3), and the fitting coefficients of the models are shown in Tables 4-6:

$$
\begin{aligned}
& y_{\mathrm{p}}=A_{\mathrm{p}}+B_{\mathrm{p}} x_{\mathrm{p}}+C_{\mathrm{p}} x_{\mathrm{p}}^{2}+D_{\mathrm{p}} x_{\mathrm{p}}^{3}, \\
& y_{\mathrm{o}}=A_{\mathrm{o}}+B_{\mathrm{o}} x_{\mathrm{o}}+C_{\mathrm{o}} x_{\mathrm{o}}^{2}+D_{\mathrm{o}} x_{\mathrm{o}}^{3}, \\
& y_{\mathrm{s}}=A_{\mathrm{s}}+B_{\mathrm{s}} x_{\mathrm{s}}+C_{\mathrm{s}} x_{\mathrm{s}}^{2},
\end{aligned}
$$

where $y_{\mathrm{p}}, y_{\mathrm{o}}$, and $y_{\mathrm{s}}$ are the SPLs of radiation noise. They represent a function of preload $x_{\mathrm{p}}$, oil supply $x_{\mathrm{o}}$, and speed $x_{\mathrm{s}}$, respectively. $A_{\mathrm{p}}, B_{\mathrm{p}}, C_{\mathrm{p}}, D_{\mathrm{p}} ; A_{\mathrm{o}}, B_{\mathrm{o}}, C_{\mathrm{o}}, D_{\mathrm{o}} ; A_{\mathrm{s}}, B_{\mathrm{s}}$, and $C_{\mathrm{s}}$ represent various coefficients. In calculation, the values of $x_{\mathrm{p}}, x_{\mathrm{o}}$, and $x_{\mathrm{s}}$ are replaced by the values of actual preload divided by 100 , actual oil supply multiplied by 100 , and actual speed divided by 1000 , respectively.

Here, the coefficient of determination, $R$-square $\left(R^{2}\right)$, is used to judge the goodness of fit. In Table 4 , the majority of $R^{2}$ values of the fitting functions are above 0.9 . Only the $R^{2}$ values of the fitting functions of points 2 and 5 are below 0.9 , both of which are 0.8956 . It indicates that there is a significant functional relationship between the radiation noise of the bearing and the preload, and a better fitting result can be obtained by the cubic polynomial. In Table 5 , the $R^{2}$ values of the fitting function between the circumferential radiation noise and the oil supply are from 0.6757 to 0.9773 . The fitting effect varies greatly with the change of the circumferential angle. As shown in Table 6 , the $R^{2}$ values of quadratic polynomial fitting for all measuring points are above 0.93 , and some even over 0.98 . Therefore, Equation (3), which is the radiation noise as a function of rotation speed, has a great fitting effect. 
TABLE 4: Fit parameters between radiation noise and preload.

\begin{tabular}{lccccc}
\hline Point & $A_{\mathrm{p}}$ value & $B_{\mathrm{p}}$ value & $C_{\mathrm{p}}$ value & $D_{\mathrm{p}}$ value & Statistics $R^{2}$ \\
\hline 1 & 185.1730 & -81.3002 & 20.3295 & -1.5993 & 0.9265 \\
2 & 245.9625 & -126.4839 & 31.7010 & -2.5215 & 0.8956 \\
3 & 232.0249 & -116.6496 & 29.3410 & -2.3504 & 0.9462 \\
4 & 203.8830 & -95.6628 & 24.1267 & -1.9259 & 0.9149 \\
5 & 188.0338 & -83.4704 & 20.9629 & -1.6556 & 0.8956 \\
6 & 184.5595 & -80.2894 & 20.1043 & -1.5822 & 0.9193 \\
7 & 192.9471 & -87.2971 & 22.0043 & -1.7400 & 0.9489 \\
8 & 167.8973 & -62.9045 & 14.7381 & -1.0393 & 0.9634 \\
9 & 145.3671 & -43.6855 & 9.5343 & -0.5667 & 0.9659 \\
10 & 154.0264 & -51.9234 & 11.9267 & -0.8037 & 0.9652 \\
11 & 156.9256 & -59.2646 & 14.6691 & -1.1274 & 0.9159 \\
12 & 161.7408 & -62.6614 & 15.3148 & -1.1630 & 0.9367 \\
\hline
\end{tabular}

TABle 5: Fit parameters between radiation noise and oil supply.

\begin{tabular}{lccccc}
\hline Point & $A_{\mathrm{o}}$ value & $B_{\mathrm{o}}$ value & $C_{\mathrm{o}}$ value & $D_{\mathrm{o}}$ value & Statistics $R^{2}$ \\
\hline 1 & 97.8581 & -22.5510 & 9.3214 & -1.0904 & 0.8892 \\
2 & 109.8348 & -34.6471 & 14.2400 & -1.7430 & 0.7050 \\
3 & 107.4400 & -33.0873 & 13.6957 & -1.6822 & 0.7667 \\
4 & 103.5529 & -28.8686 & 11.8357 & -1.4200 & 0.6757 \\
5 & 99.2633 & -23.8104 & 9.7500 & -1.1385 & 0.7361 \\
6 & 99.2276 & -24.0362 & 10.1500 & -1.2296 & 0.8113 \\
7 & 96.2595 & -18.3355 & 7.2014 & -0.7637 & 0.8623 \\
8 & 97.0491 & -17.1259 & 6.5171 & -0.6563 & 0.8494 \\
9 & 103.1481 & -24.3125 & 9.9700 & -1.1815 & 0.9773 \\
10 & 98.4295 & -20.0153 & 8.3043 & -0.9704 & 0.8839 \\
11 & 94.4929 & -18.7843 & 7.8071 & -0.9000 & 0.9067 \\
12 & 95.4962 & -21.0994 & 8.7800 & -1.0252 & 0.9455 \\
\hline
\end{tabular}

TABLE 6: Fit parameters between radiation noise and rotation speed.

\begin{tabular}{lcccc}
\hline Point & $A_{\mathrm{s}}$ value & $B_{\mathrm{s}}$ value & $C_{\mathrm{s}}$ value & Statistics $R^{2}$ \\
\hline 1 & 70.0450 & -0.0895 & 0.0365 & 0.9582 \\
2 & 71.2160 & 0.3469 & 0.0149 & 0.9723 \\
3 & 70.4380 & 0.3241 & 0.0169 & 0.9855 \\
4 & 71.2840 & -0.0310 & 0.0323 & 0.9809 \\
5 & 69.6490 & -0.0231 & 0.0353 & 0.9693 \\
6 & 70.3950 & -0.1542 & 0.0407 & 0.9580 \\
7 & 71.5570 & -0.2281 & 0.0444 & 0.9869 \\
8 & 71.8010 & -0.1077 & 0.0402 & 0.9649 \\
9 & 72.0540 & -0.3684 & 0.0593 & 0.9735 \\
10 & 71.1690 & -0.2563 & 0.0511 & 0.9660 \\
11 & 70.5550 & -0.1904 & 0.0392 & 0.9435 \\
12 & 68.9120 & 0.0968 & 0.0265 & 0.9335 \\
\hline
\end{tabular}

To predict the radiation noise at an arbitrary point in the circumferential direction, the linear interpolation method is used to calculate the radiation noise between two adjacent measuring points in the circumferential direction. The method of calculating radiation noise in the circumferential direction is shown in the following equation:

$$
y_{\theta}=\left\{\begin{array}{l}
\frac{y_{i+1}-y_{i}}{x_{i+1}-x_{i}}\left(x_{\theta}-x_{i}\right)+y_{i}, \quad i=1,2, \ldots, 11, \\
\frac{y_{1}-y_{12}}{x_{1}-x_{12}}\left(x_{\theta}-x_{12}\right)+y_{12}, \quad i=12,
\end{array}\right.
$$

where $x_{i}$ and $y_{i}$ denote the DA and the SPL of the $i$ th measuring point, respectively. $x_{\theta}$ and $y_{\theta}$ denote the DA $\theta$ and the SPL at an arbitrary direction between the range of the $i$ th and $(i+1)$ th measuring points, respectively. The unit of $\theta$ is degree.

Although the prediction model is established in a specific condition based on the experimental data of 12 measuring points with a distance of $200 \mathrm{~mm}$ away from the bearing plane and a radius of $150 \mathrm{~mm}$, it provides a reference to predict the radiation noise distribution of full ceramic angular contact ball bearings with the type of H7009C at a certain extent.

\section{Conclusion}

To investigate the radiation noise characteristics of highspeed full ceramic angular contact ball bearings, the influences of bearing preload, oil supply, and rotation speed on the radiation noise of a bearing are studied based on single factor experiment. The directivity of radiation noise in the circumferential direction is analysed. A prediction model for the radiation noise of full ceramic angular contact ball bearings with the type of $\mathrm{H} 7009 \mathrm{C}$ under specific conditions is established. The experimental results show that the radiation noise of a full ceramic angular contact ball bearing increases in general with the bearing preload; however, the two direction angles remain unchanged. Under an optimal preload, the radiation noise of bearing will have the minimum SPL, and the sound field directivity is not relatively obvious. With the increase of oil supply, the radiation noise of the full ceramic angular contact ball bearing first decreases and then increases, while the DA of the sound field stays constant, and there is an optimum oil supply to minimise the noise. As the speed increases, the radiation noise of the full ceramic angular contact ball bearing increases, and the sound field directivity becomes more obvious. The DA of the sound field in the impact load zone remains unchanged; however, the DA of the sound field in the friction load zone increases, i.e., the angle moves upward along the rotation direction. The proposed models can reflect the radiation noise characteristics of a full ceramic angular contact ball bearing commendably. The results reveal an accurate correlation between the radiation noise of the bearing and the working conditions. From the acoustic point of view, this paper provides an experimental basis for reasonable application of preload and selection of oil supply under different working conditions. The conclusion can provide a reference for further improving the performance of FCB.

\section{Data Availability}

The data used to support the findings of this study are available from the corresponding author upon request.

\section{Conflicts of Interest}

The authors declare that they have no conflicts of interest. 


\section{Acknowledgments}

This work was supported by the National Natural Science Foundation of China (Grant nos. 51675353 and 51375317).

\section{References}

[1] H. Cao, L. Niu, S. Xi, and X. Chen, "Mechanical model development of rolling bearing-rotor systems: a review," $\mathrm{Me}$ chanical Systems and Signal Processing, vol. 102, pp. 37-58, 2018.

[2] A. Gunduz, J. T. Dreyer, and R. Singh, "Effect of bearing preloads on the modal characteristics of a shaft-bearing assembly: experiments on double row angular contact ball bearings," Mechanical Systems and Signal Processing, vol. 31, pp. 176-195, 2012.

[3] L. Bizarre, F. Nonato, and K. L. Cavalca, "Formulation of five degrees of freedom ball bearing model accounting for the nonlinear stiffness and damping of elastohydrodynamic point contacts," Mechanism and Machine Theory, vol. 124, pp. 179-196, 2018.

[4] X. Zhang, Q. Han, Z. Peng, and F. Chu, "A new nonlinear dynamic model of the rotor-bearing system considering preload and varying contact angle of the bearing," Communications in Nonlinear Science and Numerical Simulation, vol. 22, no. 1-3, pp. 821-841, 2015.

[5] Y. Wang, W. Wang, S. Zhang, and Z. Zhao, "Effects of raceway surface roughness in an angular contact ball bearing," Mechanism and Machine Theory, vol. 121, pp. 198-212, 2018.

[6] S. P. Harsha, K. Sandeep, and R. Prakash, "Nonlinear dynamic response of a rotor bearing system due to surface waviness," Nonlinear Dynamics, vol. 37, no. 2, pp. 91-114, 2004.

[7] N. T. Liao and J. F. Lin, "Ball bearing skidding under radial and axial loads," Mechanism and Machine Theory, vol. 37, no. 1, pp. 91-113, 2002.

[8] Q. Han and F. Chu, "Nonlinear dynamic model for skidding behavior of angular contact ball bearings," Journal of Sound and Vibration, vol. 354, pp. 219-235, 2015.

[9] W. Zhang, S. Deng, G. Chen, and Y. Cui, "Impact of lubricant traction coefficient on cage's dynamic characteristics in highspeed angular contact ball bearing," Chinese Journal of Aeronautics, vol. 30, no. 2, pp. 827-835, 2017.

[10] S. Xi, H. Cao, and X. Chen, "Dynamic modeling of spindle bearing system and vibration response investigation," $M e$ chanical Systems and Signal Processing, vol. 114, pp. 486-511, 2019.

[11] Y. Zhang, X. H. Li, J. Hong, K. Yan, and S. Li, "Uneven heat generation and thermal performance of spindle bearings," Tribology International, vol. 126, pp. 324-335, 2018.

[12] K. Yan, Y. Wang, Y. Zhu, J. Hong, and Q. Zhai, "Investigation on heat dissipation characteristic of ball bearing cage and inside cavity at ultra high rotation speed," Tribology International, vol. 93, pp. 470-481, 2016.

[13] V. T. Than and J. H. Huang, "Nonlinear thermal effects on high-speed spindle bearings subjected to preload," Tribology International, vol. 96, pp. 361-372, 2016.

[14] D. Zheng and W. Chen, "Thermal performances on angular contact ball bearing of high-speed spindle considering structural constraints under oil-air lubrication," Tribology International, vol. 109, pp. 593-601, 2017.

[15] D. Zheng, W. Chen, and M. Li, "An optimized thermal network model to estimate thermal performances on a pair of angular contact ball bearings under oil-air lubrication," $A p$ plied Thermal Engineering, vol. 131, pp. 328-339, 2018.
[16] M. S. Patil, J. Mathew, P. K. Rajendrakumar, and S. Desai, “A theoretical model to predict the effect of localized defect on vibrations associated with ball bearing," International Journal of Mechanical Sciences, vol. 52, no. 9, pp. 1193-1201, 2010.

[17] J. Zhang, X. Lu, J. Lin, L. Ma, and J. Wang, "Dynamic analysis of a rotor-bearing-SFD system with the bearing inner race defect," Shock and Vibration, vol. 2017, Article ID 2489376, 13 pages, 2017.

[18] S. Kumar, D. Goyal, and S. S. Dhami, "Statistical and frequency analysis of acoustic signals for condition monitoring of ball bearing," Materials Today: Proceedings, vol. 5, no. 2, pp. 5186-5194, 2018.

[19] A. Glowacz, "Fault diagnosis of single-phase induction motor based on acoustic signals," Mechanical Systems and Signal Processing, vol. 117, pp. 65-80, 2019.

[20] X. T. Bai, Y. H. Wu, K. Zhang, C. Z. Chen, and H. P. Yan, "Radiation noise of the bearing applied to the ceramic motorized spindle based on the sub-source decomposition method," Journal of Sound and Vibration, vol. 410, pp. 35-48, 2017.

[21] C. Bai, H. Zhang, and Q. Xu, "Effects of axial preload of ball bearing on the nonlinear dynamic characteristics of a rotorbearing system," Nonlinear Dynamics, vol. 53, no. 3, pp. 173-190, 2007.

[22] E. Ozturk, U. Kumar, S. Turner, and T. Schmitz, "Investigation of spindle bearing preload on dynamics and stability limit in milling," CIRP Annals, vol. 61, no. 1, pp. 343-346, 2012.

[23] T. Xu, G. Xu, Q. Zhang et al., "A preload analytical method for ball bearings utilising bearing skidding criterion," Tribology International, vol. 67, pp. 44-50, 2013.

[24] S. Jiang and H. Mao, "Investigation of variable optimum preload for a machine tool spindle," International Journal of Machine Tools and Manufacture, vol. 50, no. 1, pp. 19-28, 2010.

[25] T. Zhang, X. Chen, J. Gu, and Z. Wang, "Influences of preload on the friction and wear properties of high-speed instrument angular contact ball bearings," Chinese Journal of Aeronautics, vol. 31, no. 3, pp. 597-607, 2018.

[26] F. Lv, C. Jiao, N. Ta, and Z. Rao, "Mixed-lubrication analysis of misaligned bearing considering turbulence," Tribology International, vol. 119, pp. 19-26, 2018.

[27] Z. Xie, Z. Rao, and N. Ta, "Investigation on the lubrication regimes and dynamic characteristics of hydro-hybrid bearing of two-circuit main loop liquid sodium pump system," Annals of Nuclear Energy, vol. 115, pp. 220-232, 2018.

[28] C. L. Liu, F. Guo, X. M. Li, S. Y. Li, S. L. Han, and Y. Wan, "Experimental study of elastohydrodynamic lubrication behaviour under single oil droplet supply," Tribology International, vol. 118, pp. 432-440, 2018.

[29] R. P. Glovnea, A. V. Olver, and H. A. Spikes, "Experimental investigation of the effect of speed and load on film thickness in elastohydrodynamic contact," Tribology Transactions, vol. 48, no. 3, pp. 328-335, 2005.

[30] M. Razban and M. R. Movahhedy, "A speed-dependent variable preload system for high speed spindles," Precision Engineering, vol. 40, pp. 182-188, 2015.

[31] S. Jiang and H. Mao, "Investigation of the high speed rolling bearing temperature rise with oil-air lubrication," Journal of Tribology, vol. 133, no. 2, article 021101, 2011.

[32] S. Jiang and S. Zheng, "Dynamic design of a high-speed motorized spindle-bearing system," Journal of Mechanical Design, vol. 132, no. 3, article 034501, 2010. 
[33] S. Jiang and S. Zheng, "A modeling approach for analysis and improvement of spindle-drawbar-bearing assembly dynamics," International Journal of Machine Tools and Manufacture, vol. 50, no. 1, pp. 131-142, 2010.

[34] X. Sheng, B. Li, Z. Wu, and H. Li, "Calculation of ball bearing speed-varying stiffness," Mechanism and Machine Theory, vol. 81, pp. 166-180, 2014.

[35] J. Zhang, B. Fang, Y. Zhu, and J. Hong, “A comparative study and stiffness analysis of angular contact ball bearings under different preload mechanisms," Mechanism and Machine Theory, vol. 115, pp. 1-17, 2017. 


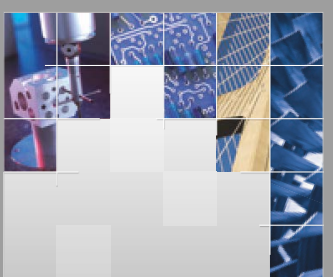

\section{Enfincering}
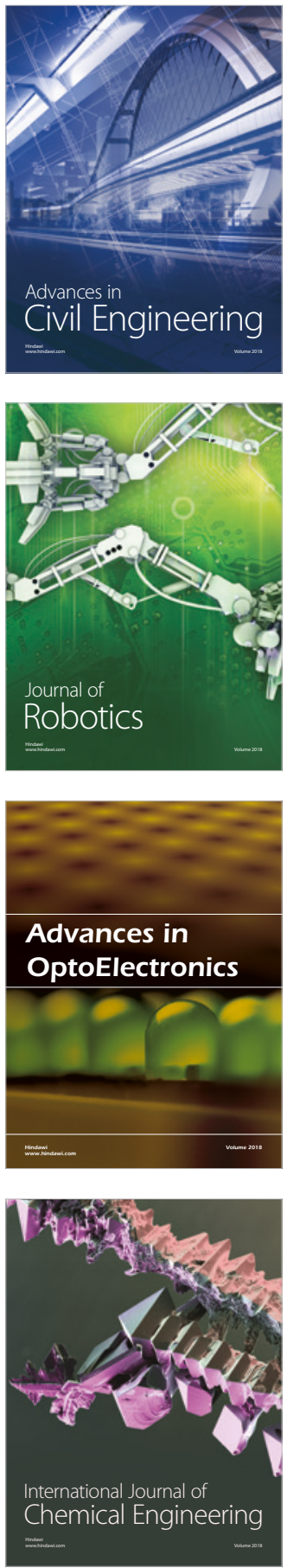

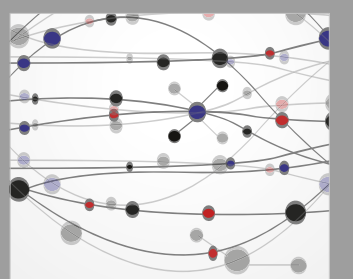

\section{Rotating \\ Machinery}

The Scientific World Journal

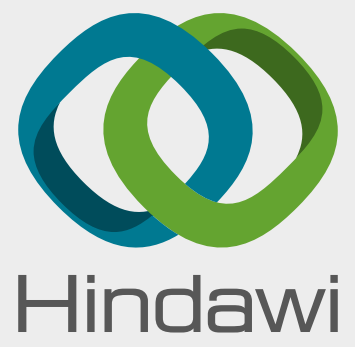

Submit your manuscripts at

www.hindawi.com
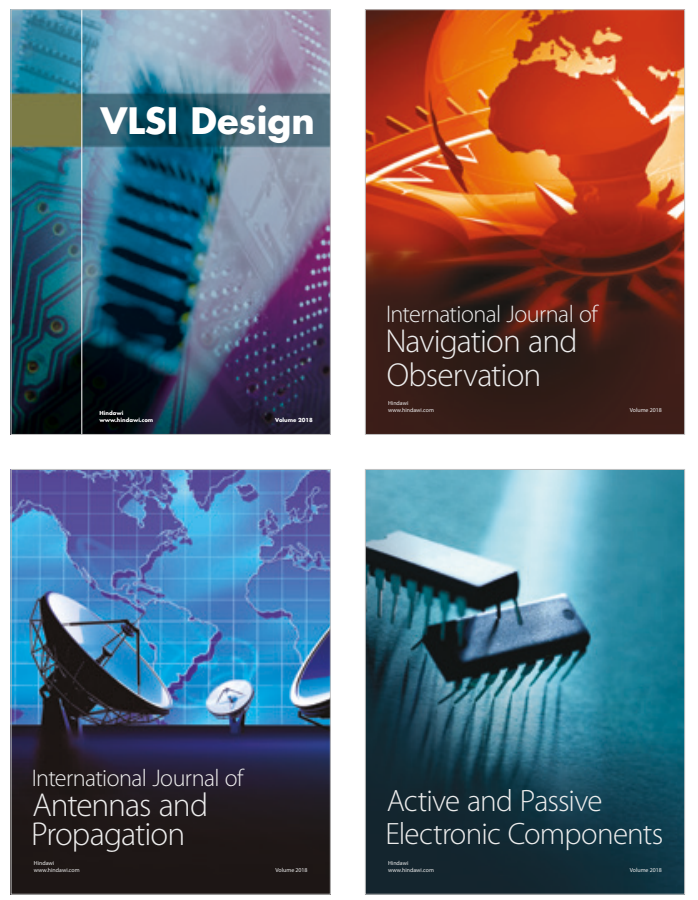
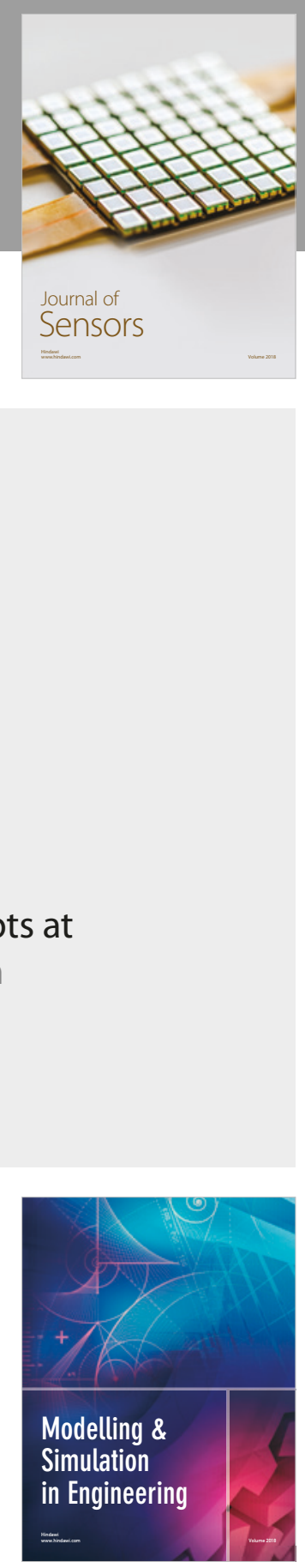

\section{Advances \\ Multimedia}
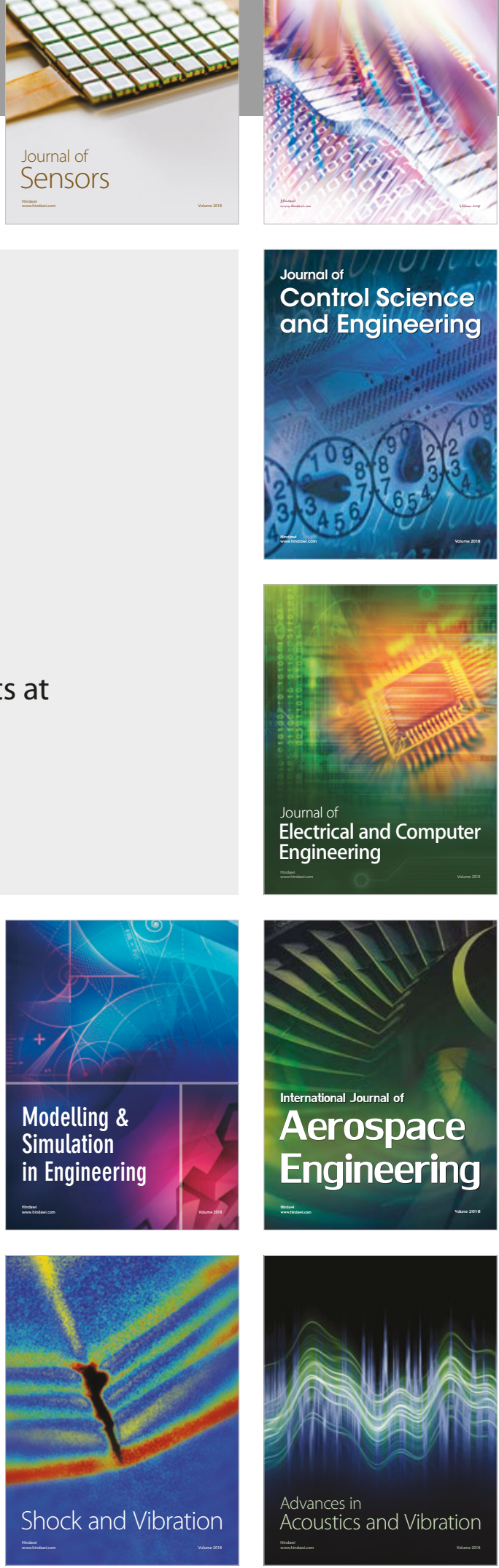